Deconstructing the side-effect effect: Separate inferences of intentions to harm and to help based on social information

\author{
Andrew J. Vonasch \\ University of Canterbury, New Zealand \\ Paul Conway \\ University of Portsmouth \\ Stephen Rowe \\ University of Canterbury, New Zealand
}

Correspondence: Dr. Andrew Vonasch

$\underline{\text { Andrew.vonasch@ canterbury.ac.nz }}$

University of Canterbury, New Zealand, Department of Psychology, Speech, and Hearing College of Science Private Bag 4800, Christchurch, New Zealand 8140 


\begin{abstract}
The classic side-effect-effect (SEE) entails judging harmful side-effects more intentional than helpful side-effects. We suggest this effect reflects two distinct components, with people drawing on different social information to disambiguate motives to harm from ambiguous motives, versus motives to help from ambiguous motives. We tested this model by altering social information in several ways. Harmful intentions were impacted by manipulations reducing the diagnosticity of the CEO's intentions by introducing external pressures (e.g., a gunman demanding they start a harmful program). This pattern suggests that perceptions of harmful intentions reflect inferences about harmful motives in the absence of external pressures. Conversely, helpful intentions were impacted by manipulations of the CEO's stated intentions. Changing the CEO's statement to be more pro-environmental flips perceptions from unintentional to probably intentional, eliminating the classic SEE difference between helping and harming intentions. Conversely, verbal justifications do not impact perceptions of harmful intent. Thus, judging harmful actions as intentional depends on unjustified trade-offs - in the absence of justifiable reasons to cause harm, harmful acts speak louder than words. Conversely, perceptions of helpful intent depend on verbal justifications clashing with normative expectations of positive self-presentation. Together, these results support the social information hypothesis, as changing relevant diagnostic social information about the CEO's intentions changed people's judgments, even to the point of eliminating the SEE.
\end{abstract}




\section{Deconstructing the side-effect effect: Separate inferences of intentions to harm and to help based on social information}

Consider a CEO who can help or harm the environment as a side effect of earning money. People judge harmful side effects as more intentional than helpful ones, a phenomenon known as the side-effect effect (SEE, Knobe, 2003). This finding has surprised and inspired philosophers and psychologists alike, who have attempted to explain it. The SEE seems counterintuitive and possibly irrational (e.g., Hindriks, Douven, \& Singmann, 2016; Knobe, 2010; Nichols \& Ulatowski, 2007; Sauer \& Bates, 2013). Whereas it is reasonable to judge intentional acts as worse (or more commendable) than accidental ones, it nonetheless seems unreasonable to assume that, in seemingly identical acts, harmful outcomes are more intentional than helpful outcomes. Yet, the SEE has been tested and found across cultures and languages (Burra \& Knobe, 2006), in children as well as in adults (Pellizzoni, Siegal, \& Surian, 2009), using many different vignettes (Leslie, Knobe, \& Cohen, 2006), and question phrasing (Pettit \& Knobe, 2015). Furthermore, in an era of $p$-hacking and failed replications, the SEE stands out as a robust, real, replicable effect (Cova, et al., 2018). However, an explanation for the SEE remains unusually elusive, despite numerous attempts (Knobe, 2010).

If anything, there are too many explanations for the SEE, rather than too few. It could be that people are biased to judge harm as intentional even when it is not, to protect themselves from harm (Alicke \& Rose, 2010). It could be that people judge harm as intentional because they imagine counterfactual realities in which the person did not do the bad thing (Knobe, 2010; Philips, et al., 2015). It could be that people judge harm as intentional because there is a tradeoff in causing harm for profit, but not in causing help (Machery, 2008). It could be that people judge harm as intentional because harming violates a social norm to protect the environment, which 
transmits useful information about the person's intentions (Uttich \& Lombrozo, 2010). Some or all of these explanations likely play some role, but none is seemingly sufficient to fully explain the effect by itself. For one thing, the SEE reflects the difference between helping and harming conditions. Yet, nearly all prominent theories focus exclusively on explaining why people think harm was intentional, even though one could equally consider why people think help was unintentional. To our knowledge, only Nadelhoffer (2004) considers this idea, and even they do not propose an explanation.

In this article, we test a unifying explanation for the SEE: the social information hypothesis. We are not alone in suggesting that people use social information to judge other people's SEE intentions (e.g., Holton, 2010, Uttich \& Lombrozo, 2010), but like most work, such approaches focus on the harm condition. Instead, we suggest that people hold different expectations about social information regarding judgments for helping and harming, and that classic SEE effects reflect this combination of expectations. Judgments of intention to harm and to help are both informed by social information, but the type of information that is most relevant about intentions is different for helping and harming. Specifically, the most relevant information about the decision to cause foreseen harm is whether doing so is justified by a greater good. In contrast, the most relevant information about the decision to cause foreseen help is whether the person indicates they do not even want to pretend to desire to help. We tested this hypothesis by altering the CEO vignette to manipulate this information, thereby changing people's judgments of the CEO's intentions in predictable ways.

The social information hypothesis is unifying in that it provides a single, overarching explanation for the asymmetry between help and harm perceptions — but it also requires acknowledging the twofold nature of the SEE. Explaining the SEE entails explaining why people 
judge harm to be intentional and why people judge help to be unintentional. The dual nature of the "effect" likely explains why isolating a single explanation for it has proven so difficult. Scholars have been looking for a single comprehensive explanation for two distinct but related phenomena: judgments of intentions to harm and help. Next, we explain the method and analyses that produce the SEE, and how they reveal two separate components requiring theoretical explanation.

\section{Unpacking the Side-Effect Effect Methods}

\section{Operationally Defining the Side-Effect Effect}

The SEE is the tendency for people to judge a side effect of the same action as more intentionally caused when the side effect is harmful than when the side effect is helpful. Thus, crucially, the SEE is not a single judgment, but a pair of related judgments. Understanding this is essential to understanding why the SEE has been so difficult to explain parsimoniously, because several different patterns of judgment are consistent with classic SEE findings. Different mechanisms can potentially produce these different patterns.

To qualify as a SEE, people must make two judgments in the following pattern:

\section{Harm intentions > help intentions}

People's judgments of another person's intentions can range from "I am confident they intended X" to "I am uncertain whether they intended X" to "I am confident they did not intend X." Thus, the SEE pattern is consistent with three types of findings:

$$
\begin{aligned}
& \text { Harm }=\text { intentional }, \text { help }=\text { unintentional } \\
& \text { Harm }=\text { intentional }, \text { help }=\text { uncertain } \\
& \text { Harm }=\text { uncertain }, \text { help }=\text { unintentional }
\end{aligned}
$$

The SEE pattern is inconsistent with three additional types of findings: 


$$
\begin{aligned}
& \text { Harm }=\text { unintentional }, \text { help }=\text { intentional } \\
& \text { Harm }=\text { unintentional }, \text { help }=\text { uncertain } \\
& \text { Harm }=\text { uncertain, help }=\text { intentional }
\end{aligned}
$$

We want to emphasize how radical this analysis of the SEE is. We are claiming that the "side-effect effect" is actually two dissociable effects: judgments of intention to harm versus unclear intentions, and judgments of intentions to help versus unclear intentions. This is important because later we will propose that, in the classic SEE vignettes, there is differentiable information available about both the person's intentions to cause harm versus help versus uncertainty. It is therefore important to measure intentions in a way that allows participants to indicate their degree of certainty versus uncertainty about the CEO's intentions.

\section{The Vignettes}

The SEE is demonstrated using a variety of different vignettes that each have a similar logical structure. They manipulate one variable at a time: the harm or help of a side effect of another action. The classic SEE vignette involves a chairman or CEO deciding whether to enact a program that makes profits and has a side effect on the environment, either harming or helping it:

The vice-president of a company went to the [CEO] and said, "We are thinking of starting a new program. It will help us increase profits, but/and it will also harm/help the environment." The [CEO] answered, "I don't care at all about harming/helping the environment. I just want to make as much profit as I can. Let's start the new program." They started the new program. Sure enough, the environment was harmed/helped. (Knobe, 2003). 
In the harm condition, participants are asked whether the CEO intentionally harmed the environment; in the help condition, participants are asked whether the CEO intentionally helped the environment. People typically make dramatically different responses to the two versions of the vignette. In the harm condition, a large majority of people thinks the CEO intentionally harmed the environment ( $82 \%$ in the original study); in the help condition, a large majority of people (77\% in the original) thinks the CEO did not intentionally help the environment. This discrepancy in judging harm and help intentions is the SEE. Thus, the SEE is the combination of two independent judgments: (1) whether someone intentionally caused a harmful side effect; (2) whether someone intentionally caused a helpful side effect.

\section{The Social Information Hypothesis}

The social information hypothesis is the idea that people use socially relevant information to infer other people's mental states, including their intentions. People are social animals who use social information in strategic ways to predict other people's behavior, to influence others, and to enhance their selves (Aronson, 2003; Baumeister, Maranges, \& Vohs, 2018; Tomasello, Carpenter, Call, Behne, \& Moll, 2005). There is a deep evolutionary history demonstrating the importance of being able to accurately judge others' intentions. Such judgments help people navigate their social environment by predicting others' behavior, and by regulating others' behavior through offering rewards and punishments (Baumeister, Masicampo, \& Vohs, 2011; Dunbar, 1998; Martin \& Cushman, 2020; Ouellette, \& Wood, 1998; Premack and Woodruff, 1978; Webb \& Sheeran, 2006; Weiner, 1993).

Judging intentions is essentially a signal detection problem: The person has intentions, but their actions only imperfectly reveal them. There is a lot of noise along with the signal of their true intentions. Judging intentions involves a great deal of uncertainty because other people 
may disguise their true intentions in an effort to enhance their impressions on others (Leary \& Kowalski, 1990; Vrij, et al., 2011). Moreover, person's intentions are invisible to everyone but themselves, thus, people must rely on the information that is available to them to infer others' intentions. That information can come in a variety of forms, including where others are looking (Calder, et al., 2002), how they are gesturing (Bretherton, McNew, Beeghly-Smith, Lamb, \& Sherrod, 1981), what they are talking about (Astington, \& Baird, 2005), and how their words compare to conversational norms (Grice, 1975).

To summarize, the social information hypothesis proposes that people judge others' intentions by observing their behavior and listening to what they say their reasons for those behaviors are - with the understanding that what they say has to be taken with a grain of salt, because people sometimes lie and hide their true intentions, especially when those intentions are bad. In the CEO vignette, the social information is different in the harm and help vignettes in key ways that produce the SEE. The social information signals that the harm was done intentionally, whereas the help was done unintentionally. The next two sections identify the relevant social information about the CEO's intentions in the harm vignette, and the help vignette, respectively.

\section{Social Information in the Harm Vignette}

Intentionality is quintessentially about purposeful action. People perceive others as acting intentionally when they purposefully cause something to happen - that is, they want to do it, believe they can do it, possess the skills to do it, intend to do it, and know they are doing it while they are doing it (Malle \& Knobe, 1997). However, there is also secondary meaning of intentionality: People perceive others as acting intentionally when they consciously decide to do something despite having strong reasons not to do it, such as because it violates social, legal, or moral norms (Nichols \& Ulatowski, 2007; Paprzycka, 2015; Uttich \& Lombrozo, 2010). For 
example, if someone robs a bank, people can say they intentionally broke the law-even though the main purpose of their action was to get the money, not to break the law. One reason people infer intentionality from norm violations (legal, moral, and other norm types) is the person almost certainly knew they were violating the norm. Except in rare circumstances, you cannot accidentally rob a bank or cheat on your spouse without realizing doing so is a violation of a social norm for which you will be punished if people find out. People are tightly attuned to social norms because failing to abide by them entails large social costs (e.g., see Cummins, 1996).

We argue certain social information is so important that people will almost always consider it in their decision-making. Norms are like this, and so are salient costs in tradeoffs. If a high school student is deciding which of two girls to ask to prom and one of them is his girlfriend, he cannot avoid considering that asking the other girl to prom may prompt the end of his current relationship. Likewise, if you are buying a new car and the salesperson tells you one car costs $\$ 5000$ more than another, you will almost always consider this information-unless you are so wealthy that price makes no meaningful difference to you. Something similar is occurring in the harm condition of the CEO vignette: the potential for harming the environment introduces a trade-off containing such important social information about a cost of the program that people assume the CEO must have considered it (Machery, 2008). Indeed, many people consider the environment to be sacred, and something that one should never harm-especially not for money (e.g., Tetlock, 2003). Thus, we conclude that people reasonably infer that the CEO likely considered the harm to the environment as part of a tradeoff.

We further propose that when someone makes a tradeoff despite the costs outweighing the benefits, people think they must have intentionally incurred the costs. For example, if someone pays $\$ 500$ for a hamburger, perceivers consider that the cost far exceeds the benefit, 
and that there are cheaper ways to get a hamburger. Given the possible alternative choices this burger eater could have made, it seems reasonable to infer they intended to pay $\$ 500$ because they could have chosen a different restaurant that likely serves cheaper hamburgers (Knobe, 2010). The same logic applies to situations where someone knowingly violates a law or norm for no good reason, like when a rich person steals a loaf of bread. The costs of violating the norm are greater than the benefits, so people can infer the theft was intentional. They could have obtained bread through other, legitimate means, so they must have chosen to steal it for the purpose of stealing it per se (as opposed to stealing as a side effect of other motives, such as hunger). So long as the bread thief was aware of the pros and cons of their decision, and elected of their own (perceived) free will to perform the act despite large costs, it is reasonable to infer they must have intentionally incurred the costs. Another way of thinking about this is that when an actor knowingly causes harms that are not justified by greater benefits, people say the actor intentionally caused the harms. This perspective has been formalized as the tradeoff-justification model (Vonasch \& Baumeister, 2017).

The tradeoff justification model proposed that people say the CEO's harm of the environment was intentional because it was unjustified. Consistent with this model, people who hold the environment to be sacred and inviolable are more likely than other people to say the CEO intentionally harmed the environment (Tannenbaum, Ditto, \& Pizarro, 2007). Furthermore, experiments manipulating both the costs and benefits of the tradeoff find that people rate harm from unjustified tradeoffs (like the CEO harm vignette) as more intentional than harm from justified tradeoffs, where either the benefits of acting were greater or the harm was less terrible (Vonasch \& Baumeister, 2017). Moreover, results using other vignettes corroborated this effect: for example, when a general sends their soldiers on a suicide mission, people say their deaths 
were intentional when the mission served no purpose and was unjustified, but that the general did not have clear intentions to cause the deaths when the mission was vital to the war effort and therefore justified (Phelan \& Sarkissian, 2009). It is worth noting that when the mission is vital and therefore justified, the general's intentions toward their soldiers are less clear. It is possible the general hates their soldiers, was hoping to send them to their deaths anyway, and the mission is simply a good excuse. However, it is perhaps more likely the general wants to protect their lives, but prioritizes winning the war over protecting the soldiers' lives — as is reasonable for a general to do. Thus, whereas unjustified tradeoffs make the decision-maker's intentions clear, justified tradeoffs provide less clear information about intentions. When there is a good reason to incur a cost, it becomes less clear whether the decision-maker intended to incur the cost or if the cost was truly an unintended byproduct. It becomes uncertain.

To summarize our account of why people think the CEO intentionally harmed the environment, we argue that 1). People use social information to infer people's intentions. 2). Certain social information is so important that people infer others almost certainly considered it in their decision-making. 3). The CEO was given this kind of information, so must have considered it. 4). Many people think the CEO's decision was unjustified-that harming the environment is not justified by the profit. 5). People who freely and knowingly cause harm without sufficient justification must have done so intentionally. 6). The CEO freely and knowingly caused harm without sufficient justification. Therefore, it is reasonable to infer that the CEO intentionally harmed the environment. If this account is correct, then people's judgments of the CEO's intentions should become uncertain after manipulating the CEO's decision to lack social information that almost certainly would be considered. Furthermore, manipulating the CEO's decision to be less free-coerced by external pressure - should decrease 
certainty about the CEO's true intentions. However, manipulating the CEO's words should make little difference in people judgments because the CEO's decision-making reveals intentions to harm.

\section{Social Information in the Help Vignette}

Why do people say that the CEO did not intentionally help the environment? We propose that whereas the judgments that the CEO intentionally harmed the environment is primarily based on the unjustified tradeoff the CEO consciously decided to make, judgments that the CEO did not intentionally help the environment are primarily based on the words the CEO uses. In the help vignette, there is no tradeoff (Machery, 2008). The program does two good things-makes profit and helps the environment. Therefore, the CEO's decision to run the program, which they explicitly state is done to make profit, reveals little about their intentions toward the environment. The decision itself is compatible with either a pro-environment CEO who is enthusiastic about helping the environment, with a CEO who is totally indifferent toward the environment, or even with a CEO who hates the environment but loves profit more. There is no clear information in the decision. Thus, the decision is not what produces the judgment the CEO did not intentionally help the environment - the CEO's words do.

The CEO says: "I don't care at all about helping the environment." This statement reveals a callous, counter-normative attitude toward the environment that is clearly incompatible with the CEO desiring and intending to help it. Counterfactual thinking suggests the CEO could have said many things about the effect on the environment that would reveal a more positive attitude toward it (Knobe, 2010). Furthermore, one would expect that even if the CEO did not actually care about helping the environment, they might have at least pretended to like the idea of helping the environment to appear more socially desirable (Crowne \& Marlow, 1960; Krumpal, 2013). 
Indeed, conversational norms suggest an expectation for people to take credit for intending positive outcomes, as doing so potentially enhances reputation with little possible downside, as motives in non-trade-off cases are ambiguous. To flagrantly violate such conversational norms communicates information beyond the overt phrasing, implying counter-normative distaste for the positive outcome (Grice, 1975). Thus, even if you take the CEO at their word that they are indifferent to the environment, rather than actively hostile as their tone implies, it is clear that they do not have a positive attitude toward the environment. Their words are a clear signal that even though they ran a program that helped the environment, they did so purely in order to gain profit and not in order to help the environment.

To summarize the social information hypothesis's account of why people think the CEO did not intentionally help the environment, we argue that 1 . People use social information to infer people's intentions, drawing upon conversational norms. 2. The CEO's decision to run the helpful program provides very little information about the CEO's intentions. 3. However, the CEO's words make clear the CEO did not intentionally help the environment. If so, then manipulating the CEO's words to express gladness at helping the environment should make the CEO's help seem likely intentional, rather than almost certainly unintentional. Furthermore, manipulating the CEO's decision to be less free — coerced by external pressure — should decrease certainty about the CEO's true intentions.

\section{Predictions and current research}

Below, we report two experiments that manipulated social information in the CEO vignette, and measured intentions on scales allowing participants to report uncertainty. We varied the social information in several ways to increase or decrease judgments of intention. Some vignettes were designed to produce judgments that the CEO intended the side effect: the 
classic harm vignette, and a help vignette where the CEO says they are glad to help the environment. Some vignettes were designed to produce judgments that the CEO did not intend the side effect: the classic help vignette. Still other vignettes were designed to reduce the signal of the CEO's intentions, such that we predicted people would indicate uncertainty about the CEO's intentions: a neutral side effect condition involving no tradeoff, and two conditions with strong external pressure on the CEO to run the program, thereby reducing certainty about the CEO's true intentions. The social information hypothesis predicts that when the social information clearly indicates the CEO's intentions, as in the classic harm and help vignettes, the SEE should occur, but that when diagnostic social information is reduced, people should report more uncertainty in their judgments, potentially reducing or eliminating the SEE.

Furthermore, the social information hypothesis predicts key differences in the sources of information for judging intentions to help and harm. The tradeoff justification model predicts that judgments of intentions to harm should mostly stem from the tradeoff the CEO makes, such that altering the tradeoff to be justified should reduce people's confidence that the CEO intentionally harmed. In contrast, because there is no tradeoff in the help conditions, help judgments should mostly stem from the words the CEO uses-if the CEO expresses gladness at helping they should be judged as intentionally helping.

All manipulations, measures, and exclusions are reported below. Anonymized data (including three pretests/close replications) are available at:

\section{https://osf.io/za4jw/?view_only=0760afccd968415cbc0724f5578e9712.}

\section{Study 1: Deconstructing the side-effect effect}

This study used five versions of the CEO vignette to test the social information hypothesis. In addition to the normal help and harm vignettes (Knobe, 2003), a neutral (non- 
morally relevant) control condition was added where the CEO's program changed the color of the product packaging. The social information hypothesis posits that the default judgment is to be uncertain about the CEO's intentions unless social information signals them. Thus, a neutral side effect will provide very little information about the CEO's intentions toward the side effect, so people will be uncertain about whether the effect was intentional. We measured intentionality on a scale allowing participants to indicate uncertainty (i.e., a scale with a midpoint labeled unsure whether it was intentional), unlike typical measures that force participants into a dichotomous judgment of whether the action was intentional or unintentional. We predicted that, despite the uncertainty option, participants would indicate they were relatively certain the CEO intentionally harmed the environment, and relatively certain the CEO did not intentionally help the environment, but express uncertainty regarding CEO intentions in the neutral case.

We added two additional vignettes from Guglielmo \& Malle (2010) that change the CEO's words, but not their actions. In the glad to help condition, the CEO said they were "thrilled about helping the environment," and in the regretful harm condition, the CEO said it "would be unfortunate if the environment got harmed." We predicted that the CEO's words would cause a larger shift in participant judgments in the help vignette than harm version of the vignette, because choosing to run a program known to cause harm provides more information about the intentions, thus diminishing the importance of verbal explanation. Thus, participants would have one main source of information in the help vignette (the CEO's words), and another in the harm vignette (the CEO's decision).

\section{Method}

As preregistered (https://aspredicted.org/blind.php? $\mathrm{x}=\mathrm{d} 4 \mathrm{cj} 3 \mathrm{v}$ ), we decided a priori to recruit $~ 500$ American participants on Mturk, slightly oversampling: $N=504$ (280 male, 221 
female, 2 other, 1 did not answer). Sensitivity analysis reveals $80 \%$ power to detect an effect of size $d=.40$. Participants were randomly assigned to read one of five versions of the CEO vignette, and answer two questions: "Did the CEO intentionally [harm the environment/help the environment/change the packaging]?" from -3 (definitely unintentional), through 0 (unsure whether it was intentional), to 3 (definitely intentional). "How clear are the CEO's intentions to [harm the environment/help the environment/change the packaging]?" from 1 (very unclear) to 7 (very clear). ${ }^{1}$ They then reported demographics, and were debriefed.

The five vignettes were as follows:

\section{Harm}

The vice-president of a company went to the CEO and said, "We are thinking of starting a new program. It will help us increase profits, but it will also harm the environment." The CEO answered, "I don't care what the program does to the environment. Let's start the program." They started the new program. Sure enough, the environment was harmed and the company made a profit.

\section{Neutral}

The vice-president of a company went to the CEO and said, "We are thinking of starting a new program. It will help us increase profits, but it will also change our product's packaging." The CEO answered, “I don't care about the product packaging. Let's start the program.” They started the new program. Sure enough, the packaging was changed and the company made a profit.

\section{Help}

\footnotetext{
${ }^{1}$ In retrospect, this was a poorly worded question. The results were mostly as expected, where the CEO's intentions to harm was clearer than his intentions to change the packaging-except in the help vignette, probably because participants did not know how to rate how clear the CEO's lack of intentions was.
} 
The vice-president of a company went to the CEO and said, "We are thinking of starting a new program. It will help us increase profits, and it will also help the environment." The CEO answered, "I don't care what the program does to the environment. Let's start the program." They started the new program. Sure enough, the environment was helped and the company made a profit.

\section{Regret Harm}

The vice-president of a company went to the CEO and said, "We are thinking of starting a new program. It will help us increase profits, but it will also harm the environment." The CEO answered, "It would be unfortunate if the environment got harmed. But my primary concern is to increase profits. Let's start the new program." They started the new program. Sure enough, the environment was harmed and the company made a profit.

\section{Glad to help}

The vice-president of a company went to the CEO and said, "We are thinking of starting a new program. It will help us increase profits, and it will also help the environment." The CEO answered, "I'm thrilled about helping the environment! And it's crucial that we increase profits. Let's start the new program." They started the new program. Sure enough, the environment was helped and the company made a profit.

\section{Results}

The results were as predicted. A significant ANOVA, $F(4,499)=128, p<.001, \eta^{2}=$ .506 , revealed differences between conditions (Figure 1, Table 1). Tukey-corrected planned contrasts tested the differences between specific conditions according to theory (Table 1). Side-effect effect 
As predicted, the SEE replicated. Participants thought harming $(M=2.31, S D=1.29)$ was more intentional than helping the environment $(M=-1.98, S D=1.46), t(499)=20.11, p<$ $.001, d=3.11$. Moreover, as predicted, participants rated harm as clearly intentional $(M=2.31$ out of a maximum of 3$)$, and help as clearly unintentional $(M=-1.98$ out of a minimum of -3$)$.

\section{Neutral side effect}

As predicted, participants were almost completely uncertain about whether the neutral side effect was intentional, with a slight tendency toward saying it was somewhat intentional $(M$ $=0.40$ out of a -3 to +3$)$. As predicted, participants judged the neutral effect as significantly more intentional than the helping side effect, $t(499)=-11.16, p<.001, d=1.39$, and significantly less intentional than the harming side effect, $t(499)=9.02, p<.001, d=1.16$.

\section{The CEO's words}

As predicted, the CEO's words had a much greater influence on judgments of intent in the helping conditions than in the harming conditions. Notably, in the helping conditions, participants thought the CEO's expressed indifference about helping the environment meant the help was unintentional $(M=-1.98$ out of -3 to +3$)$, but when the CEO instead expressed feeling glad to help the environment, people thought this meant the help was intentional $(M=1.42$ out of -3 to +3$)$. This enormous difference was, of course, statistically significant, $t(499)=-15.87, p<$ $.001, d=2.31$. Furthermore, changing the CEO's words in the helping condition eliminated nearly $80 \%$ of the SEE. The initial 4.29-point difference between the classic help and harm SEE conditions decreased to just a 0.90-point difference when the CEO expressed a desire to help the environment. Thus, judgments of the CEO's intentions to help depended mostly on the CEO's words: people think they intentionally helped if they said they were glad to help, but that they did not intentionally help if they expressed unconcern about helping the environment. 
In contrast, the CEO's words had limited influence on judgments that the CEO intentionally harmed the environment. Expressing regret $(M=1.89, S D=1.29)$ resulted in a small and nonsignificant decrease in judged intentions to harm the environment compared to the typical harm condition $(M=2.31, S D=1.29), t(499)=1.99, p=.273, d=0.33$. Consistent with our model, the decision to cause harm speaks louder than words. Thus, whereas expressing gladness dramatically altered judgments that the CEO intentionally helped the environment, expressing regret about causing harm had minimal effect.

Overall, changing the CEO's words to clarify their intentions largely eliminated the classic SEE, consistent with the pattern of means in Guglielmo \& Malle, 2010, studies 4a and 4b. Comparing the two rephrased conditions decreased the SEE to nonsignificance, $t(499)=2.22, p$ $=.174, d=0.34($ Table 1$)$. 


\section{Intentions}

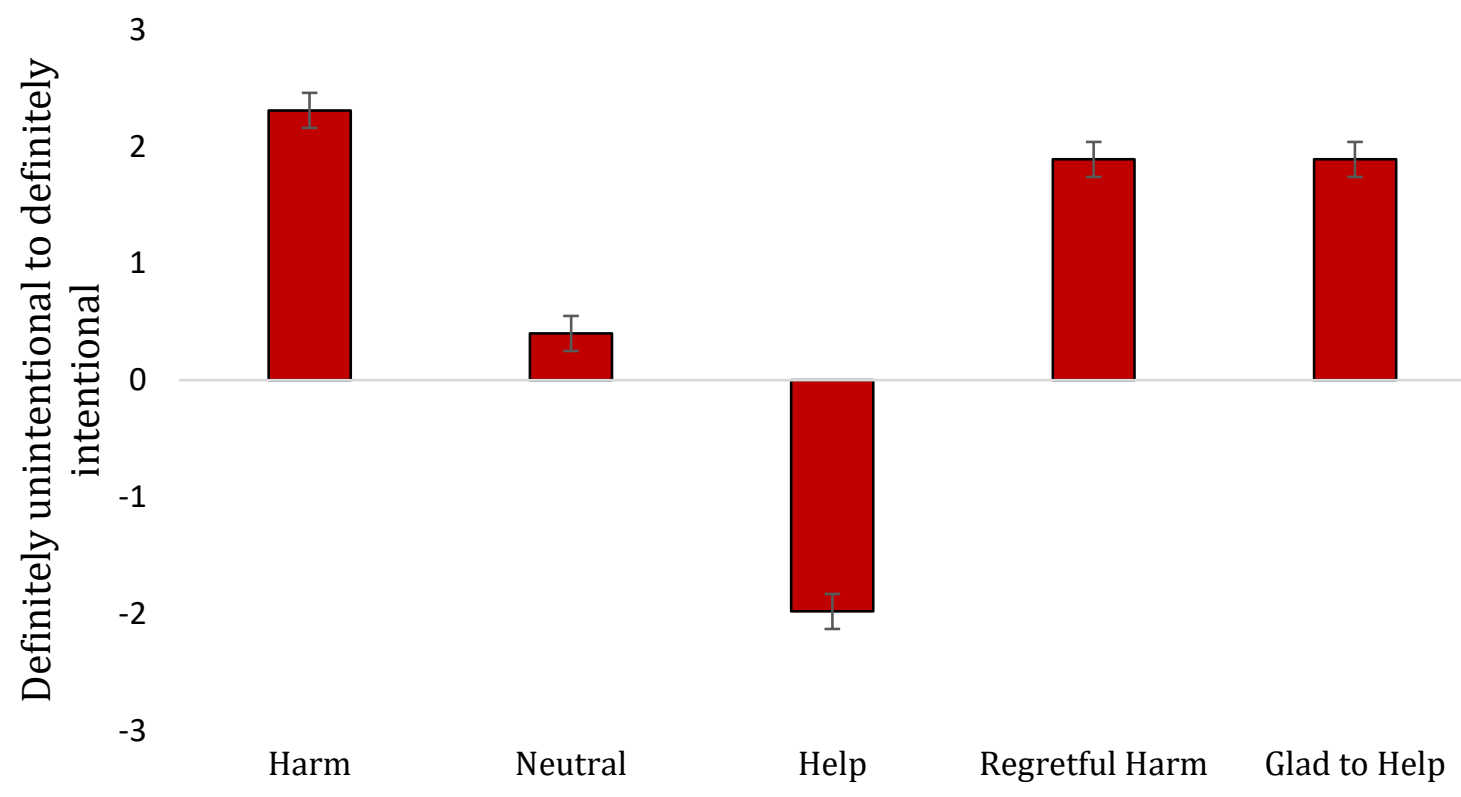

Figure 1. Intentionality ratings by vignette. Error bars indicate standard error.

Planned and Post Hoc Comparisons

\begin{tabular}{|c|c|c|c|c|c|c|c|}
\hline \multicolumn{3}{|c|}{ Comparison } & \multirow[b]{2}{*}{ Mean Difference } & \multirow[b]{2}{*}{ SE } & \multirow[b]{2}{*}{ df } & \multirow[b]{2}{*}{$\mathbf{t}$} & \multirow[b]{2}{*}{$\mathbf{p}_{\text {tukey }}$} \\
\hline Vignette & & Vignette & & & & & \\
\hline \multirow[t]{4}{*}{ Harm } & - & Help & 4.294 & 0.214 & 499 & 20.11 & $<.001$ \\
\hline & - & Neutral & 1.912 & 0.212 & 499 & 9.02 & $<.001$ \\
\hline & - & Regretful Harm & 0.424 & 0.213 & 499 & 1.99 & 0.273 \\
\hline & - & Glad to Help & 0.898 & 0.212 & 499 & 4.23 & $<.001$ \\
\hline \multirow[t]{3}{*}{ Help } & - & Neutral & -2.382 & 0.214 & 499 & -11.16 & $<.001$ \\
\hline & - & Regretful Harm & -3.870 & 0.215 & 499 & -18.04 & $<.001$ \\
\hline & - & Glad to Help & -3.396 & 0.214 & 499 & -15.87 & $<.001$ \\
\hline \multirow[t]{2}{*}{ Neutral } & - & Regretful Harm & -1.488 & 0.213 & 499 & -6.99 & $<.001$ \\
\hline & - & Glad to Help & -1.014 & 0.212 & 499 & -4.77 & $<.001$ \\
\hline Regretful Harm & - & Glad to Help & 0.474 & 0.213 & 499 & 2.22 & 0.174 \\
\hline
\end{tabular}

Table 1. Planned and Post Hoc comparisons between each condition, Tukey-adjusted to minimize Type I error. Planned comparisons in bold. 


\section{Discussion}

The results support several predictions of the social information hypothesis. First, when the side effect was morally neutral, participants indicated they felt uncertain about the CEO's intentions - they did not assume all non-harmful side effects must be unintentional. This suggests that when people say that helping the environment seemed unintentional, they really mean it — unintentionality is not the default judgment for side effects. Indeed, participants rated helping the environment as clearly unintentional, and significantly less intentional than the neutral side effect. Moreover, people were clear in their ratings of the CEO's intention to harm to the environment. Participants rated the harm as clearly intentional, and significantly more intentional than the neutral side effect. The take-home message is that people's judgments of the CEO's decision closely followed the available social information in the vignette, leading people to judge various side effects as either clearly unintentional, clearly intentional, or neither clearly intentional or unintentional.

Second, the CEO's words provided more information about the CEO's intentions in the help vignette than in the harm vignette. The CEO's expression that they "don't care what the program does to the environment" is apparently vital for producing the judgments that the CEO did not intentionally help the environment, because only such phrasing violates conversation norms that people expect others to take credit for intending positive outcomes. If the CEO instead says they are thrilled to help, consistent with conversational norms for positive outcomes, people's judgments of their intentions completely reversed from the classic case: they say the CEO intentionally helped the environment. This pattern is consistent with our model, because the CEO's decision transmits very little information about their intentions to help (i.e., it is unclear which positive outcome, profit or environment, drove the decision), rendering their verbal 
statement more informative for drawing inferences. To our knowledge, no other model would predict these results, because they only make predictions about intentions to harm.

Third, when the side effect harms the environment, participants largely ignored the CEO's words in favor of drawing inferences directly from their actions. The tradeoff justification model suggests that in the face of grave negative consequences they could hardly ignore (violating social and moral norms), the CEO nonetheless chose to forge ahead, choosing profit over those consequences. This action paints a clear picture of the CEO's motivational priorities that render their empty words largely irrelevant; after all, there is no conversational norm surrounding expectations to take credit for intending negative outcomes, as there is no reputational benefit to be gained. Accordingly, the CEO's expression of regret at harming the environment barely budged people’s judgments regarding his intentions - suggesting they inferred this statement was a weak attempt at socially desirable posturing aiming to poorly mask the true intentions revealed by their selfish action. Together, these findings provided support for the social information hypothesis.

In Study 2, we tested a further prediction: that providing additional justification for the harmful action — external pressure to make a given decision — would attenuate or eliminate the SEE. External pressure can provide sufficient explanation of the CEO's action to reduce or eliminate remaining uncertainty about their motives. Hence, even though people may intuit that the CEO foresees the environmental harm the program will cause, their actions may be motivated by acceptable reasons (e.g., fear for their life rather than just greed) and hence do not reveal malicious intention. 


\section{Study 2: Under pressure — $\_$side effects and certainty about intentions}

Study 2 examined the informational value of external pressure on the CEO's decision. We hypothesized that when the situation compelled the CEO to run the program, their decisionmaking would be less informative about their intentions to affect the environment. For example, if the CEO was forced at gunpoint to run the program, people should think the CEO neither intentionally harmed, nor unintentionally helped the environment — the gun is sufficient to explain their motivation, eliminating inferences about motives toward the environment.

We manipulated three levels of external pressure: none, low, and high. In the no pressure condition, the CEO ran the program freely and voluntarily to make profit. In the some pressure condition, the CEO ran the program to avoid being fired by the board of directors. In the high pressure condition, the $\mathrm{CEO}$ ran the program to avoid getting shot by a crazed gunman. We employed a 3 (external pressure level) $\times 2$ (help vs. harm environment) between-subjects factorial design. We predicted that added pressure on the CEO to run the program would decrease the diagnosticity of their decision-making process, making their intentions less clear. Therefore, we predicted that adding pressure would make their intentions to harm the environment more uncertain, and their lack of intentions to help the environment more uncertain. Thus, adding pressure should decrease the SEE.

\section{Method}

The study was preregistered (https://aspredicted.org/blind.php?x=fu2aa2). We aimed for 600 participants, and obtained 601 American Mturkers, but excluded one participant for providing an impossible age, leaving a final sample of 600 (385 male, 214 female, 1 declined to report). Sensitivity analysis reveals $80 \%$ power to detect an effect of size $d=.40$. We employed the same dependent variables as Study 1, the key variable being: "Did the CEO intentionally 
[help/harm] the environment?" from -3 (definitely unintentional), through 0 (unsure whether it was intentional), to 3 (definitely intentional). The no pressure vignettes were the help and harm vignettes from previous studies. The harm versions of the external pressure vignettes are below.

Threat of being fired. At a meeting with the $\mathrm{CEO}$ and the board of directors of a company, the vice-president of a company told the CEO, "We are thinking of starting a new program. It will help us increase profits, but it will also harm the environment.” The chairman of the board said "It's in the company's best interest to run this program." He turned to the CEO and said "You will run this program or you will be fired." The CEO answered, "OK. I don't care what the program does. I'll start the program, just don't fire me!" They started the new program. Sure enough, the environment was harmed and the company made a profit.

Threat of being killed. The vice-president of a company went to the CEO and said, "We are thinking of starting a new program. It will help us increase profits, but it will also harm the environment." Right then, another man burst through the door and pointed a loaded gun at the CEO's head. The man with the gun said "If you don't start this program I will kill you!" The CEO answered, “OK! I don't care what the program does. I'll start the program, just don't shoot me!” They started the new program. Sure enough, the environment was harmed and the company made a profit.

\section{Results}

We replicated the classic SEE. However, as predicted, the size of the SEE decreased with added external pressure on the CEO's decision. There were main effects of harm, $F(1,593)=$ 402.69, $p<.001, \eta_{\mathrm{p}}{ }^{2}=.404$, pressure, $F(2,593)=4.63, p=.010, \eta_{\mathrm{p}}{ }^{2}=.015$, and a significant interaction, $F(2,593)=75.25, p<.001, \eta_{\mathrm{p}}{ }^{2}=.202$ (Figure 2) 
As predicted, increasing external pressure decreased certainty regarding the CEO's intentions both to harm and to help the environment. Planned comparisons revealed that the more pressure was on the CEO, the less certain participants were that the CEO intended to harm the environment. Participants were less certain the harm was intentional in the gun to the head condition than in the fired condition, $F(1,593)=68.00, p<.001, \eta_{\mathrm{p}}{ }^{2}=.103$, and in the no pressure condition, $F(1,593)=101.86, p<.001, \eta_{\mathrm{p}}^{2}=.147$. They were marginally less certain the harm was intentional in the fired condition than in the no pressure condition, $F(1,593)=$ $3.06, p=.081, \eta_{\mathrm{p}}^{2}=.005$.

Planned comparisons also revealed that the more pressure there was on the CEO, the less certain participants were that the CEO did not intend to help the environment. Participants were less certain the help was unintentional in the gun condition than the fired condition, $F(1,593)=$ $20.53, p<.001, \eta_{\mathrm{p}}^{2}=.033$, and the no pressure condition, $F(1,593)=41.37, p<.001, \eta_{\mathrm{p}}^{2}=$ .065. They were marginally less certain the help was unintentional in the fired condition than in the no pressure condition, $F(1,593)=3.39, p=.066, \eta_{\mathrm{p}}^{2}=.006$.

As predicted, the difference in intentionality between harm and help was attenuated by the degree of external pressure on the CEO's decision-making. In the no pressure condition, $\operatorname{harm}(M=2.10, S D=1.22)$ was seen as more intentional than help $(M=-2.04, S D=1.41)$, $t(594)=18.43, p<.001, \eta_{\mathrm{p}}{ }^{2}=.364$. In the fired condition, harm $(M=1.70, S D=1.39)$ was seen as more intentional than help $(M=-1.62, S D=1.58)$, but the difference was smaller, $t(594)$ $=14.56, p<.001, \eta_{\mathrm{p}}^{2}=.262$. In the gun condition, harm $(M=-.18, S D=2.00)$ was only seen as marginally more intentional than help $(M=-.59, S D=1.86), t(594)=1.84, p=.067, \eta_{\mathrm{p}}{ }^{2}=.006$.

As predicted, at higher levels of external pressure, the CEO's intentions seemed less clear to participants, $F(2,597)=24.68, p<.001, \eta_{\mathrm{p}}{ }^{2}=.076$. They reported that the CEO's intentions 
were clearer in the no pressure condition $(M=5.01, S E=.14)$ than in the fired condition $(M=$ 4.25, $S E=.15), F(1,597)=13.77, p<.001, \eta_{\mathrm{p}}{ }^{2}=.023$, and in the gun condition $(M=3.57, S E=$ $.15), F(1,597)=49.27, p<.001, \eta_{\mathrm{p}}^{2}=.076$. Moreover, participants rated the CEO's intentions as clearer in the fired condition than in the gun condition, $F(1,597)=10.60, p<.001, \eta_{\mathrm{p}}{ }^{2}=.017$.

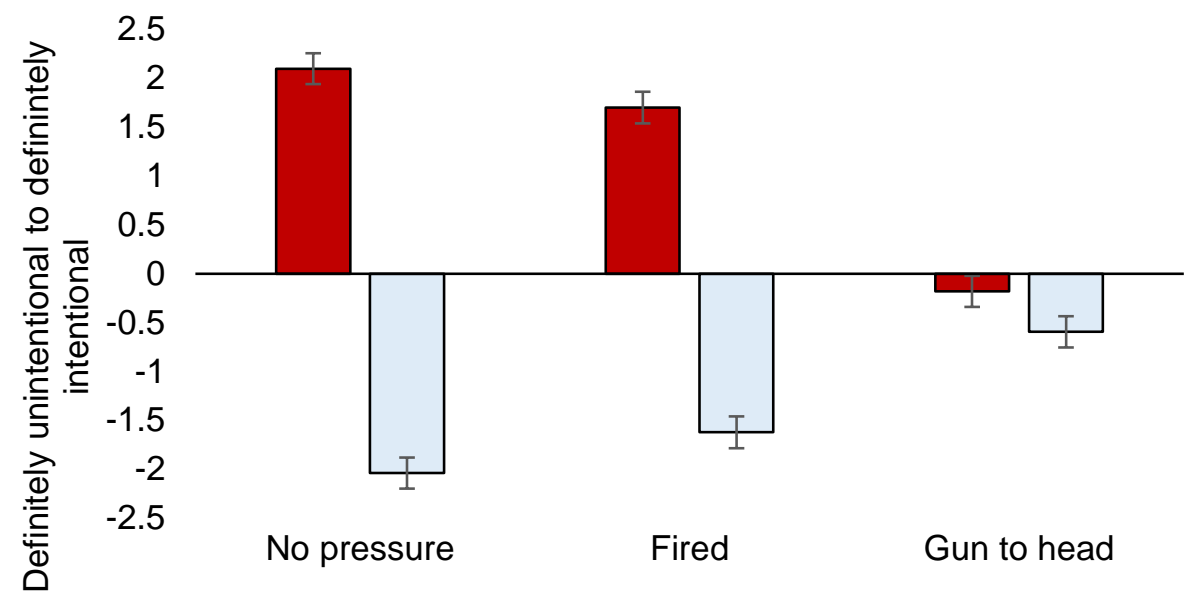

Type of external pressure to run the program

$\square$ Harm $\square$ Help

Figure 2. External pressure on the CEO's decision decreased participants' certainty about the CEO's intentions.

\section{Discussion}

As predicted, external pressure on the CEO's decision decreased people's certainty regarding the CEO's intentions. This finding fits neatly with the social information hypothesis. When less social information is available (because external pressures mask internal motivation), people become less certain regarding the decision-makers' internal motivation. Moreover, external pressure decreased certainty in both the intentionality of harm and the unintentionality of help. If the SEE were merely a bias toward seeing harm as intentional, then one might predict a gun to the head would reduce judgments of intentionality, because any action done while 
forced at gunpoint is presumably less intentional. However, that is not what we found in the help condition. People were less certain that helping was unintentional. This further corroborates the hypothesis that social information produces the SEE.

\section{General Discussion}

Numerous explanations for the SEE have been proposed, but the current studies reveal why it has been so difficult to understand. Most researchers have been looking for a single bias or competence that explains why people think harm is intentional (Knobe, 2010). However, there are two separate judgments — of help and of harm — that are sensitive to different sources of social information, respectively: the CEO's decision-making itself, and the CEO's verbal explanation of their motives. The social information perspective can explain both of these effects.

Harming the environment seems intentional because the tradeoff the CEO makes involves causing harm for an unjustified reason-greed — and unjustified harms are usually intentional. In other words, the CEO seems to have knowingly and willingly caused damage in pursuit of self-interest, which violates social and moral mores, and therefore they seem to have intentionally chosen this path. Changing the CEO's words to be more socially desirable makes no real difference in judgments of their intentions to cause harm, because their decision-making signals that the harm is intentional. People reasonably infer that their expressed regret appears as just empty window-dressing next to their actions that speak louder than words.

Helping the environment seems unintentional because the motivation is ambiguous when a single action has multiple positive outcomes - was the true motivation profit or to make positive change? - but the CEO's words clarify their intention. When the CEO expresses a socially desirable intention to help the environment, consistent with conversational norms, 
people seem willing to offer the benefit of the doubt (i.e., that even though they profit too, profit does not appear to be the sole motivation). However, the curious counter-normative blasé dismissal of the environment in the classic case renders it irrelevant to offer such benefit of the doubt: they fully admit to unconcern for the environment, a social cue that clarifies their intentions, because such a statement violates conversational norms for intending positive outcomes. Conversely, judgments of the intention to cause a morally neutral side effect further support our model. There was no information about the intentions from either the CEO's decision-making or the CEO's words, so people reported being uncertain about the CEO's intentions.

Moreover, judgments of the CEO's intentions under external pressure further support our model. When powerful external forces constrain people to perform a behavior, there is less room for personal intentions and motivations to influence said behavior. Hence, external pressure reduces information about the CEO's intentions, thereby increasing uncertainty. It becomes very difficult to ascertain the CEO's true attitudes towards the environment when they have a compelling (life-or-death) reason to start the program regardless of foreseen negative consequences and their feelings about those consequences. Accordingly, when the CEO is threatened with firing unless they start the program, the SEE is reduced in magnitude, and when the CEO is forced at gunpoint to run the program, the SEE is eliminated. These findings support our claim that people use social information to judge the CEO's intentions.

The social information hypothesis incorporates several factors discovered in prior research, like norm violation (Uttich \& Lombrozo, 2010), making tradeoffs (Machery, 2008), social roles and responsibilities (Rowe, et al., 2020), and breaking taboos (Tannenbaum, et al., 2007). Each is a cue about the CEO's decision-making, but not the whole picture. For example, 
unjustified violations of norms can signal the CEO intentionally harmed, but not that the help was unintentional - in contrast, the CEO's harsh words signal the help was unintentional, but have no bearing on their intentions to harm. Moreover, people consider the CEO's relevant counterfactuals (Knobe, 2010) to determine whether the harm was compelled or freely done, and whether the callous remark signals intentions.

On its face, the CEO vignette appears to hold the amount of information about motives constant, as the CEO always explicates their true motive and describes the environmental impact as a side effect, and only the word 'harm' changes to 'help' across condition. Hence, one could argue that both conditions reflect identical intention information. However, altering this single word changes numerous other socially relevant bits of information, such as whether the CEO violated a norm (Uttich \& Lombrozo, 2010), whether the CEO made a tradeoff (Machery, 2008), and whether the CEO's reasons for running the program justified causing the side effect (Vonasch \& Baumeister, 2017). These alterations provide crucial relevant information about the CEO's decision-making process that clarifies their intentions, leading to a different inference in the harming than in the helping SEE case. In short, people can infer the CEO's intentions by learning about the way they make decisions and what they say about those decisions.

\section{Limitations and Future Directions}

The largest limitation of this research is the sole reliance on versions of the CEO vignette. There are other vignettes and dependent variables (e.g., desire [Guglielmo \& Malle, 2010], freedom, causation, doing/allowing [Phillips, Luguri, \& Knobe, 2015]; knowledge [Beebe \& Buckwalter, 2010]; blame [Hindriks, Douven, \& Singmann, 2016]) in the literature, but we decided to focus on the CEO vignette and intentions. We believe our explanation (or something closely related) may also explain the other vignettes and dependent variables attributed to the 
SEE, but we use the CEO vignette and the original dependent variable (intentionality) as a constrained and controlled test case, before testing more diffuse claims.

Although Study 2 found that external pressure on a decision-maker reduced the SEE, the social information hypothesis is somewhat vague about how much pressure will reduce it by how much. External pressure in the form of a gun to the head significantly altered judgments of intentionality, but the CEO who was told they would be fired if they did not run the program only reduced the SEE by a little bit. One reason is participants might have believed the CEO was not compelled by the situation to run the program - they could have quit instead. People may have assumed the CEO had plenty of money already, would receive an attractive compensation upon quitting, and could easily find employment elsewhere - and thus getting fired was a minor burden not worth the tradeoff of harm to the environment. Future research might clarify which external pressures people view as sufficient to warrant such tradeoffs - for example, if the CEO must keep their job to pay for something important, like their partner's chemotherapy, they might view such pressure as coercive and therefore the CEO's decision less revealing of intention-and whether there are any cross-cultural differences in what external pressures are deemed sufficient.

\section{Implications}

The present research has several key implications. First: two separate effects contribute to the side-effect effects, not just one. Past research has focused almost exclusively on explaining why people think the harmful side effect was intended, but that is only half of the story. This research helps explain why people think the helpful side effect was unintended, and that turns out to be one way to eliminate the SEE. Altering the CEO's statement to be less hostile toward the pro-environment position eliminated the difference between judgments of intention to harm and intention to help the environment. 
Reducing the intention signal of the CEO's decision-making also eliminated the SEE. The CEO did the same program with helpful or harmful side effects, but when a gunman forced the CEO to make that decision, people were uncertain about the CEO's true intentions toward the environment. This is because the unjustified decision-making process normally informs people about the CEO's intentions to harm the environment, and when a gunman forces the CEO to make a particular decision, that decision no longer transmits information about the CEO's intentions.

The social information hypothesis proposes that people's intention judgments mostly follow the available social information in the vignettes. The information in these vignettes shapes judgments in the pattern of the SEE, although that is not the only pattern of judgment that can occur for the intentionality of side effects. One could presumably craft vignettes in which both harm and help are clearly unintentional (for example, if the CEO had very good reasons to believe the program would not affect the environment, was kept unaware of the program's existence, or instructed the vice president not to run the program but the VP ran it anyway). Similarly, one could presumably craft vignettes in which both harm and help are clearly intentional (for example, the CEO decides to run a program that only affects the environment and makes no profit, or the CEO's secret diary reveals their true intentions to affect the environment). It would be a mistake to assume that harmful side effects will invariably be judged as intentional, or that helpful side effects will invariably be judged as unintentional. The question is why identical phrasing about helpful versus harmful side effects reliably produces the SEE. The social information hypothesis proposes the phrasing of the vignettes imply subtle information about intentions. 
Most claims to explain the SEE take the form of: we found a variable that statistically significantly reduces the size of the SEE. Not here. These manipulations eliminated the SEE. This is strong evidence in support of the social information hypothesis. The literature is full of too many explanations, but we have attempted to unify them into a single powerful framework: social information.

SEE scholars should strongly consider measuring perceived intentions on scales allowing people to indicate degrees of uncertainty. Both continuous and more traditional dichotomous measures reliably produce the side-effect effect (Nakamura, 2018). However, dichotomous measures can obscure the meaning of responses by making uncertain judgments appear certain. A major advantage of using fine-grained measures of intentions is the ability to distinguish judgments of "I am confident they intended X" from "I am leaning toward thinking they intended X, but am uncertain." Moreover, continuous measures can distinguish "I am uncertain whether they intended X" from "I am confident they did not intend X," which turns out to be essential for understanding judgments in the help case.

The social information hypothesis suggests some important other domains to study how people judge intentions. One is politics. People judge unjustified harms as intentional—but individuals differ on which political tradeoffs they consider to be unjustified. These differences could produce hostile attributions of contrapartisans' political motives - the idea that the other side is intentionally making life worse for my side (Goya-Tochetto, et al., 2021). Another domain is explaining the powerful forces behind life events. People judge unjustified harms as intentional - could this explain why people develop conspiracy theories about big, unjustifiably harmful events like 9/11, the Kennedy assassination, and the COVID-19 pandemic (Vonasch, et al., 2021)? Another domain is romantic relationships. People judge unjustified harms as 
intentional—could lack of communication about the justifying reasons for harmful behavior help explain marital dissatisfaction (Fincham, et al., 2000)? Another domain is money. Would people infer hidden costs to explain otherwise unjustifiably generous economic exchange offers (Vonasch, et al., 2021).

\section{Conclusion}

Social information explains why people think the CEO intentionally harmed, but unintentionally helped the environment. 


\section{References}

Aronson, E. (Ed.). (2003). Readings about the social animal. Macmillan.

Astington, J. W., \& Baird, J. A. (Eds.). (2005). Why language matters for theory of mind. Oxford University Press.

Barrouillet, P., Bernardin, S., Portrat, S., Vergauwe, E., \& Camos, V. (2007). Time and cognitive load in working memory. Journal of Experimental Psychology: Learning, Memory, and Cognition, 33(3), 570-585.

Baumeister, R. F., Maranges, H. M., \& Vohs, K. D. (2018). Human self as information agent: Functioning in a social environment based on shared meanings. Review of General Psychology, 22(1), 36-47.

Baumeister, R. F., Masicampo, E. J., \& Vohs, K. D. (2011). Do conscious thoughts cause behavior?. Annual Review of Psychology, 62, 331-361.

Beebe, J. R., \& Buckwalter, W. (2010). The epistemic side-effect effect. Mind \& Language, 25(4), 474-498.

Bretherton, I., McNew, S., Beeghly-Smith, M., Lamb, M. E., \& Sherrod, L. R. (1981). Early person knowledge as expressed in gestural and verbal communication: When do infants acquire a theory of mind.

Calder, A. J., Lawrence, A. D., Keane, J., Scott, S. K., Owen, A. M., Christoffels, I., \& Young, A. W. (2002). Reading the mind from eye gaze. Neuropsychologia, 40(8), 1129-1138.

Cova, F., Strickland, B., Abatista, A., Allard, A., Andow, J., Attie, M., ... \& Cushman, F. (2018). Estimating the reproducibility of experimental philosophy. Review of Philosophy and Psychology, 1-36. 
Crowne, D. P., \& Marlowe, D. (1960). A new scale of social desirability independent of psychopathology. Journal of Consulting Psychology, 24(4), 349.

Cummins, D. D. (1996). Evidence for the innateness of deontic reasoning. Mind \& Language, 11, 160-190.

Díaz, R., Viciana, H., \& Gomila, A. (2017). Cold side-effect effect: Affect does not mediate the influence of moral considerations in intentionality judgments. Frontiers in Psychology, 8, 295.

Fincham, F. D., Harold, G. T., \& Gano-Phillips, S. (2000). The longitudinal association between attributions and marital satisfaction: Direction of effects and role of efficacy expectations. Journal of Family Psychology, 14(2), 267-285.

Gigerenzer, G., \& Todd, P. M. (1999). Simple heuristics that make us smart. Oxford University Press, USA.

Grice, H. P. (1975). Logic and conversation. In Speech acts (pp. 41-58). Brill.

Goya-Tochetto, D., Kay, A., Vuletich, H., Vonasch, A. J., \& Payne, K. (working paper 2021). The Partisan Trade-off Bias: When Political Polarization Meets Policy Trade-offs.

Guglielmo, S., \& Malle, B. F. (2010). Can unintended side effects be intentional? Resolving a controversy over intentionality and morality. Personality and Social Psychology Bulletin, $36(12), 1635-1647$.

Hindriks, F., Douven, I., \& Singmann, H. (2016). A new angle on the knobe effect: Intentionality correlates with blame, not with praise. Mind \& Language, 31(2), 204-220.

Knobe, J. (2003). Intentional action and side effects in ordinary language. Analysis, 63(3), 190194. 
Knobe, J. (2010). Person as scientist, person as moralist. Behavioral and Brain Sciences, 33(4), 315-329.

Krumpal, I. (2013). Determinants of social desirability bias in sensitive surveys: a literature review. Quality \& Quantity, 47(4), 2025-2047.

Leslie, A. M., Knobe, J., \& Cohen, A. (2006). Acting intentionally and the side-effect effect: Theory of mind and moral judgment. Psychological Science, 17(5), 421-427.

Malle, B. F., \& Knobe, J. (1997). The folk concept of intentionality. Journal of Experimental Social Psychology, 33(2), 101-121.

Nadelhoffer, T. (2004). On praise, side effects, and folk ascriptions of intentionality. Journal of Theoretical and Philosophical Psychology, 24(2), 196-213.

Nichols, S., \& Ulatowski, J. (2007). Intuitions and individual differences: The Knobe effect revisited. Mind \& Language, 22(4), 346-365.

Ouellette, J. A., \& Wood, W. (1998). Habit and intention in everyday life: The multiple processes by which past behavior predicts future behavior. Psychological Bulletin, 124(1), 54-74.

Paprzycka, K. (2015). The omissions account of the Knobe effect and the asymmetry challenge. Mind \& Language, 30(5), 550-571.

Payne, B. K., \& Gawronski, B. (2010). A history of implicit social cognition: Where is it coming from? Where is it now? Where is it going. Handbook of implicit social cognition: Measurement, theory, and applications, 1, 1-15.

Pellizzoni, S., Siegal, M., \& Surian, L. (2009). Foreknowledge, caring, and the side-effect effect in young children. Developmental Psychology, 45(1), 289-295. 
Pettit, D., \& Knobe, J. (2009). The pervasive impact of moral judgment. Mind \& Language, 24(5), 586-604.

Phillips, J., Luguri, J. B., \& Knobe, J. (2015). Unifying morality’s influence on non-moral judgments: The relevance of alternative possibilities. Cognition, 145, 30-42.

Premack, D., \& Woodruff, G. (1978). Does the chimpanzee have a theory of mind? Behavioral and Brain Sciences, 1(4), 515-526.

Tomasello, M., Carpenter, M., Call, J., Behne, T., \& Moll, H. (2005). Understanding and sharing intentions: The origins of cultural cognition. Behavioral and Brain Sciences, 28(5), 675691.

Sauer, H., \& Bates, T. (2013). Chairmen, cocaine, and car crashes: The Knobe effect as an attribution error. The Journal of Ethics, 17(4), 305-330.

Sripada, C. S. (2010). The deep self model and asymmetries in folk judgments about intentional action. Philosophical Studies, 151(2), 159-176.

Tannenbaum, D., Ditto, P. H., \& Pizarro, D. A. (2007). Different moral values produce different judgments of intentional action. Unpublished manuscript, University of California-Irvine.

Tetlock, P. E. (2003). Thinking the unthinkable: Sacred values and taboo cognitions. Trends in Cognitive Sciences, 7, 320-324.

Uttich, K., \& Lombrozo, T. (2010). Norms inform mental state ascriptions: A rational explanation for the side-effect effect. Cognition, 116(1), 87-100.

Vonasch, A. J., \& Baumeister, R. F. (2017). Unjustified side effects were strongly intended: Taboo tradeoffs and the side-effect effect. Journal of Experimental Social Psychology, $68,83-92$. 
Vonasch, A. J., Doré, \& Felicite, (working paper, 2021). The Psychological Origins of Conspiracy Theory Beliefs: Big Events with Small Causes Amplify Conspiratorial Thinking.

Vonasch, A. J., Mofradidoost, R., \& Gray, K. (working paper, 2021). When people reject free money: Phantom costs and the psychology of economic exchange.

Vrij, A., Leal, S., Mann, S. A., \& Granhag, P. A. (2011). A comparison between lying about intentions and past activities: Verbal cues and detection accuracy. Applied Cognitive Psychology, 25(2), 212-218.

Webb, T. L., \& Sheeran, P. (2006). Does changing behavioral intentions engender behavior change? A meta-analysis of the experimental evidence. Psychological Bulletin, 132(2), 249-268.

Weiner, B. (1993). On sin versus sickness: A theory of perceived responsibility and social motivation. American Psychologist, 48, 957.

Young, L., Cushman, F., Adolphs, R., Tranel, D., \& Hauser, M. (2006). Does emotion mediate the relationship between an action's moral status and its intentional status? Neuropsychological evidence. Journal of Cognition and Culture, 6(1-2), 265-278. 